\title{
Implementasi Push Notification Pada Sistem Peminjaman Sarana dan Prasarana Berbasis Website
}

\author{
Mohammad Imron ${ }^{1}$, Gagas Restu Sutikno², Islakhun Nur Dazki ${ }^{3}$ \\ 1,2,3 Universitas Amikom Purwokerto \\ Fakultas Ilmu Komputer \\ JI.Let Jend Pol Soemarto Depan SPN Purwokerto 53123 Purwokerto Utara \\ e-mail: '1imron@amikompurwokerto.ac.id, ${ }^{2}$ gagasrest@gmail.com, ${ }^{3 i s l a d z a k @ g m a i l . c o m ~}$
}

\begin{abstract}
Abstrak
Dalam membantu kegiatan yang dilakukan mahasiswa Universitas Amikom Purwokerto menyediakan sarana dan prasarana yang dapat menunjang kegiatan seperti halnya proyektor, laptop, perlengkapan laboratorium dan ruang kelas. Saat ini sistem peminjaman yang berlaku masih menggunakan pencatatan didalam buku peminjaman, sehingga masih kurang efektif dalam membantu proses peminjaman yang dilakukan, permasalahan pengembalian peralatan tersebut mengakibatkan sulitnya proses pencarian peralatan yang belum dikembalikan. Tujuan pembuatan sistem pengelolaan sarana prasarana untuk membantu proses pengelolaan secara akurat dan aktual. Penerapan teknologi Push Notification atau Messaging server sendiri dapat menampilkan pemberitahuan berbasis website meskipun tidak membuka web browser secara langsung, sehingga dapat melakukan broadcast message, metode pengembangan yang dilakukan yaitu dengan metode waterfall. Metode pengujian sendiri menggunakan blackbox dan acceptance testing, dari hasil pengujian yang sudah dilakukan dengan blackbox bahwa aplikasi fitur yang diuji berjalan sesuai dengan harapan dan pengujian acceptance testing berupa kuisioner menggunakan skala pengukuran likert dari jumlah sampel 30 responed didapat $79 \%$ tergolong kriteria baik.
\end{abstract}

Kata kunci: Peminjaman, sarana prasarana, Waterfall, Push Notification, Aplikasi Web

\begin{abstract}
In helping activities carried out by Amikom Purwokerto University students, they provide facilities and infrastructure that can support activities such as projectors, laptops, laboratory equipment and classrooms. Currently the current lending system still uses the records in the lending book, so it is still less effective in assisting the lending process, the problem of returning the equipment results in the difficulty of finding equipment that has not been returned. The purpose of making an infrastructure management system is to help the management process accurately and actually. The application of Push Notification technology or the Messaging server itself can display websitebased notifications even though it does not open a web browser directly, so that it can broadcast messages, the method of development carried out is the waterfall method. The testing method itself uses blackbox and acceptance testing, from the results of tests that have been done with the blackbox that the tested feature application runs in accordance with expectations and acceptance testing testing in the form of a questionnaire using a Likert measurement scale of the number of 30 response samples obtained $79 \%$ classified as good criteria.
\end{abstract}

Keywords: Lend, infrastructure, Waterfall, Push Notification, Web Application

\section{Pendahuluan}

Perkembangan tentang dunia pendidikan di Indonesia hiingga saat ini mengalami kemajuan yang sangat baik, begitu juga dengan Perguruan Tinggi yang ada di Kabupaten Banyumas, salah satu Perguruan Tinggi swasta yang ada di
Banyumas yaitu Universitas Amikom Purwokerto juga menjadi bagian Perguruan Tinggi yang mengalami peningkatan yang sangat baik. Untuk meningkatkan kualitas layanan selayaknya Perguruan Tinggi terus meningkatkan kualitas layanan yang diberikan kepada mahasiswa sebagai stakeholder utama Perguruan Tinggi. 
Proses belajar mengajar saja tidak cukup jika tidak didukung dengan fasilitas-fasilitas penunjang lainnya seperti laboratorium Komputer, sebagai salah satu sarana pelayanan untuk kebutuhan mahasiswa perlu memperhatikan kepuasan mahasiswa terhadap layanan yang ada di Perguruan Tinggi agar kualitas pendidikan dimasa depan lebih baik.

Sarana dan prasarana Perguruan Tinggi Universitas Amikom Purwokerto merupakan bagian yang sangat penting dalam sistem pelayanan untuk mendukung berjalannya belajar mengajar, keberhasilan Perguruan Tinggi sebagai unit khusus dalam mendukung pencapaian visi dan misi khususnya dalam pelayanan sarana prasarana perlu miningkatkan kualitasnya dengan selalu melakukan evaluasi, aktifitas perkuliahan di suatu intitusi merupakan kegiatan yang hampir setiap saat membutuhkan ruangan atau laboratorium komputer sebagai penujang kegiatan belajar mengajar. Selain kegiatan perkuliahan adapun juga Unit Kegiatan Mahasiswa (UKM) yang membutuhkan ruangan atau peralatan untuk dapat terlaksananya kegiatan tersebut, perlu menanyakan ketersediaan ruangan atau peralatan serta izin ruangan diluar jam perkuliahan ke bagian yang bersangkutan terlebih dahulu (Akademik, 2012).

Berdasarkan hasil wawancara dengan bagian kerumah tanggaan dan Laboratorium Komputer yang masih ada di Perguruan Tinggi Universitas Amikom Purwokerto memiliki kendala diantaranya penanganan proses peminjaman yang memakan waktu sehingga kurang efektif, sulitnya proses pencarian pada saat pengembalian barang yang akan dikembalikan, pencarian ruangan yang kosong cukup memkan waktu dan terlebih jika terjadi kesalahan akan mengakibatkan terjadinya jadwal yang berbenturan dengan jadwal perkuliahan dalam satu waktu.

Website dapat diartikan sebagai kumpulan halaman-halaman yang dapat digunakan untuk menampilkan informasi berupa teks, gambar, animasi, suara, dan gabungan yang bersifat statis maupun dinamis tergantung dari nilai data atau parameter yang dikirimkan oleh user ke webserver (Ayu \& Permatasari, 2018),(Fridayanthie, 2016) yang tersimpan disebuah internet atau disebut webserver (Pahlevi et al., 2018). Penelitian yang telah dilakukan berkaitan dengan pengembangan dan pengujian sistem berbasis web yang menerapkan teknologi web push notification (Faisol \& Rahmadianto, 2019), untuk peminjaman sarana dan prasaranan di beberapa instansi dengan menggunakan metode waterfall yang menghasilkan aplikasi berbasis website berjalan dengan baik sesuai yang diharapkan (Wijaya, 2017). Penelitian sebelumnya yang telah dilakukan juga bertujuan agar sistem menjadi lebih efisien seperti halnya sistem peminjaman dan pengembalian yang sering bermasalah dan memakan waktu yang lama sehingga membutuhkan perubahan dengan memanfaatkan teknologi yang ada (Putra et al, 2019)

Dengan menerapkan teknologi web push notification diharapkan dapat membantu pegawai atau peminjam dalam menerima pemberitahuan ketika adanya pengajuan yang masuk. Web Push Notification merupakan metode yang mengirimkan data ke browser atau mobile device secara realtime, yang mana dengan adanya web push notification ini dapat memberi kenyamanan pengguna dalam bentuk informasi (Wangsaputra et al., 2016), (Rahmatulloh et al., 2019). Informasi yang dibutuhkan pengguna menggunakan aplikasi tersebut, cara kerja sistem tersebut bekerja seperti pesan singkat atau short message ketika pesan masuk makan akan muncul notifikasi untuk memberi tahukan tentang data atau pesan yang telah dikirim atau ketika layar pengguna dijalankan meskipun pengguna membuka web atau tidak (Isikligil et al., 2017), (Rahmatulloh et al., 2019). Dari penelitian ini bertujuan untuk mengelola dan memanajemen sistem peminjaman ruangan dan alat di Universitas Amikom Purwookerto yang diharapkan mampu memberikan efektifitas serta keakuratan baik bagi peminjam maupun pengelola.sistem

\section{Metode Penelitian}

Penelitian ini dilaksanakan di Universitas Amikom Purwokerto, penetapan lokasi penelitian didasarkan atas dasar pertimbangan akses data, data sebagai penelitian tersebut belum banyak diolah sehingga informasi terbaru masih sedikit diinstansi. Pada penelitian ini menggunakan metode menurut (Putri \& Wulandari, 2016) model air terjun (waterfall) yaitu metode 
dengan model sekuensi linier atau alur hidup klasik yang pendekatan alurnya secara terurut. Untuk tahapan dari metode yang diterapkan pada penelitian ini meliputi analisis, desain, pengkodean, pengujian dan hingga tahap pendukung (support).

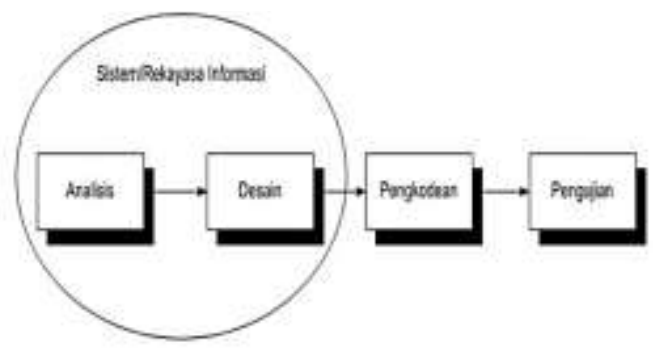

Gambar 1. Ilustrasi Model Waterfall Sumber:Sukamto dan Shalahuddin (2014:29).

1. Analisis,merupakan kebutuhan perangkat lunak yang proses pengumpulannya dilakukan secara intensif agar dapat menspesifikasikan kebutuhan perangkat lunak yang dibutuhkan user, sehingga kebutuhan perangkat lunak dapat didokumentasikan sesuai dengan kebutuhan.

2. Desain,merupakan langkah perancangan proses pembuatan perangkat lunak yang merepresentasikan antar muka dari struktur data, sehingga tahapan ini menjadi langkah berikutnya agar desain dapat diimplementasikan menjadi tahapan program selanjutnya

3. Pengkodean, menjadi tahapan yang sebelumnya merancang struktur atau arsitektur perangkat lunak yang harus ditranslasikan ke dalam program perangkat lunak sehingga tahapan ini memberikan gambaran perangkat lunak yang telah dirancang bahwa aplikasi sudah ditahap selesai.

4. Pengujian, pada tahapan ini sendiri memberikan gambaran bahwa perangkat lunak dari sisi fungsional sudah diuji secara keseluruhan, dikarenakan tahap ini untuk mendeteksi atau meminimalisir kesalahan yang terjadi dan memastikan bahwa perangkat lunak yang telah diselesaikan sesuai dengan yang diharapkan user.

\section{Hasil dan Pembahasan}

\section{Analisis Masalah}

Permasalahan yang terjadi pada proses peminjaman di Universitas Amikom Purwokerto masih dilakukan dengan cara manual sehingga terjadi penumpukan data dalam bentuk buku besar, ditambah keterlambatan pengembalian, pencarian data yang tidak efektif hingga memakan waktu dan terjadinya form peminjaman yang hilang ataupun rusak. Dari hasil permasalahan yang terjadi maka dibuatlah sistem berbasis website dengan menerapkan teknologi push notification agar mempermudah pelayanan khususnya peminjaman sarana dan prasarana.

\section{Perancangan Proses}

Pada tahapan ini peneliti menggunakan UML (Unified Modeling Language) untuk memodelkan sistem yang dibuat peneliti, dari tahapan ini terdiri dari macam-macam diagram yang dapat diimplementasikan diantaranya Use Case Diagram, Sequence Diagram, Acitivity Diagram, dan Class Diagram.

\section{a) Use Case Diagram}

Use Case Diagram memiliki fungsi untuk mengetahui fungsi apa saja yang ada di dalam sebuah sistem dan siapa saja yang terlibat dalam fungsi tersebut, dengan menggunakan use case diagram ini pengguna dapat memahami dari alur sistem yang akan dibangun sesuai dengan permasalahan yang terjadi di Universitas Amikom Purwokerto terkait dengan peminjaman sarana dan prasarana.

Pada use case diagram aplikasi pengelolaan dan peminjaman sarana dan prasarana juga digambarkan aktor yang berhubungan dalam pengoperasian aplikasi, pada aplikasi tersebut terdapat 2 aktor yang berperan yaitu Administrator dan Pengguna (user). Aplikasi pengelolaan dan peminjaman sarana dan prasarana dengan menggunakan metode web push notification yang dilakukan dalam lingkup interen Universitas Amikom Purwokerto. Pengguna aplikasi dapat melakukan interaksi dengan fitur yang pertama register agar dapat login dengan menunggu verifikasi dari admin. 


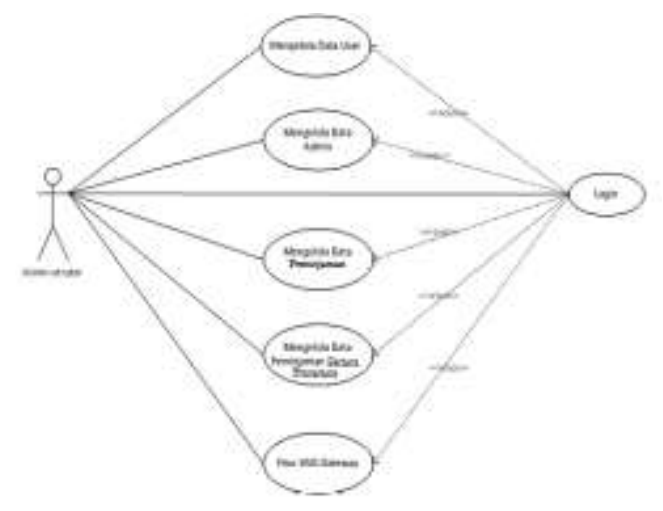

Gambar 2. Use Case Diagram administrator

b) Sequence Diagram Administrator dan User

Sequence diagram digunakan untuk menggambarkan interaksi antar objek di dalam dan sekitar sistem berupa message yang digambarkan terhadap waktu. Berikut merupakan sequence diagram untuk aplikasi pengelolaan dan peminjaman sarana dan prasarana berbasis website dengan menggunakan metode push notification. Pada gambar 3.diagram tersebut menjelaskan proses dari semua administrator, mulai dari mengakses halaman login dengan memasukan username dan password menuju database untuk mengecek data admin, apabila data valid maka admin akan dialihkan ke halaman dasboard dan jika data yang dimasukan tidak valid makan akan menampilkan alert error bahwa data tidak valid sehingga harus mengisikan sesuai dengan username dan password. Pada gambar 4. Diagram tersebut menjelaskan proses admin mengelola data admin apakah data dapat diubah atau tidak dan jika valid makan akan muncul alert sukses.

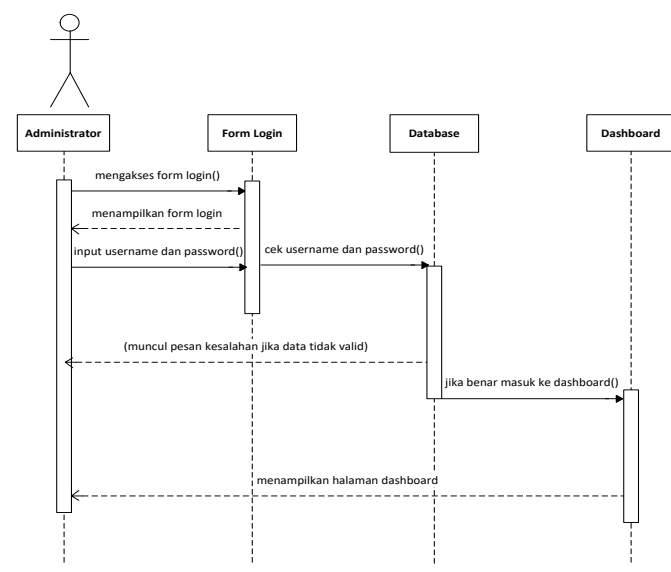

Gambar 3. Sequence Diagram login halaman Admin

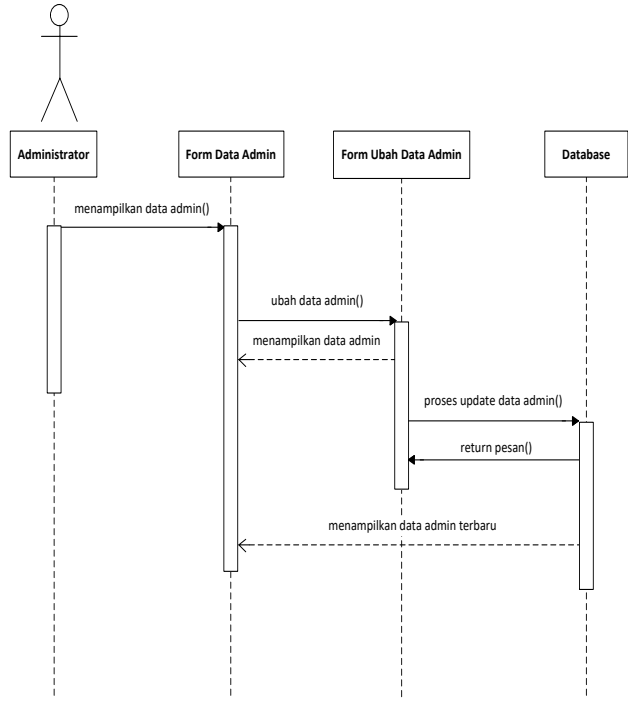

Gambar 4. Sequence Diagram mengelola data Admin.

Untuk Sequence Diagram verifikasi data peminjaman dapat dilihat pada gambar 5 , proses verifikasi data tersebut untuk mengecek data peminjaman apakah data yang dimasukan oleh user valid atau tidak dan apabila data valid maka akan dilanjutkan ke proses verifikasi data peminjaman dan data yang ada pada tabel data peminjaman.sedangkan diagram pada gambar 6., menjelaskan proses tolak data peminjaman.

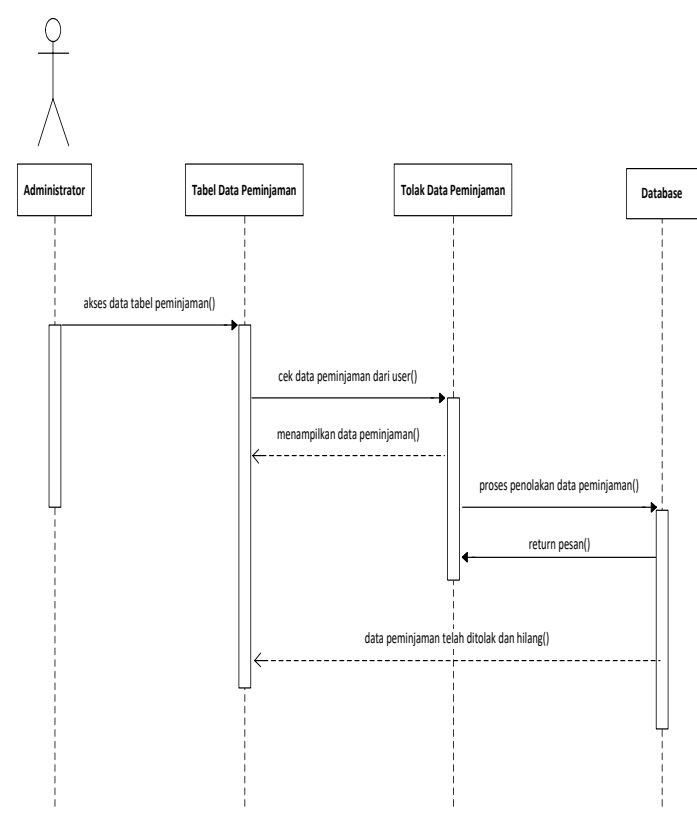

Gambar 5. Sequence Diagram verifikasi data peminjam 


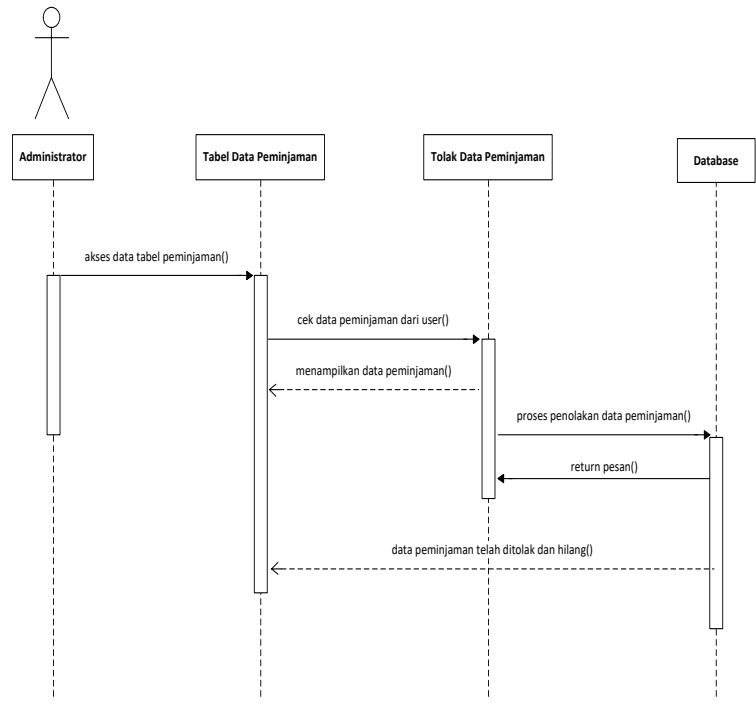

Gambar 6. Sequence Diagram tolak data peminjam

Pada Sequence Diagram User sendiri menjelaskan proses register user sebagai hak akses user untuk masuk kedalam sistem maka harus melakukan terlebih dahulu register yang dapat dilihat juga pada gambar 7., jika data valid maka akan dialihkan ke form login dan akan mendapatkan alert sukses untuk melakukan verifikasi dapat melalui cek email dan kontak person yang dimasukan oleh user pada saat mendaftar, sedang sequence diagram user sediri dapat dilihat pada gambar 8 yang menggambarkan proses input data pengguna atau peminjam.

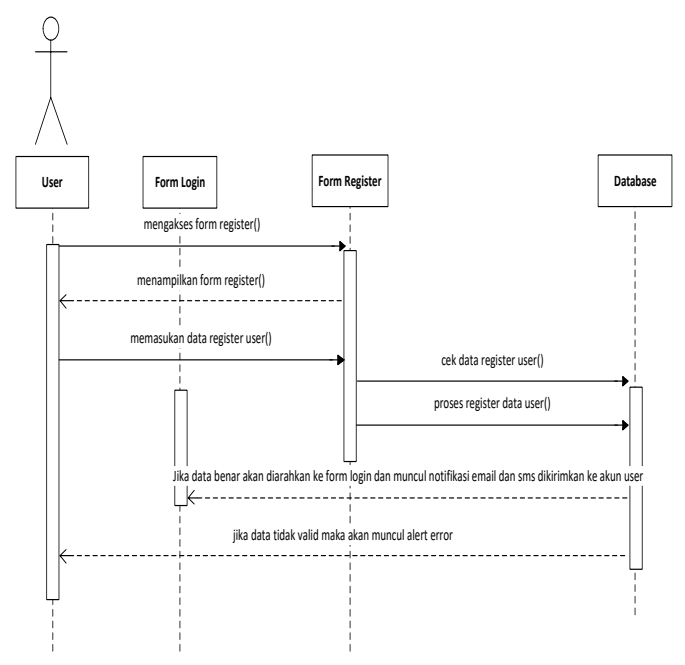

Gambar 7. Sequence Diagram Register

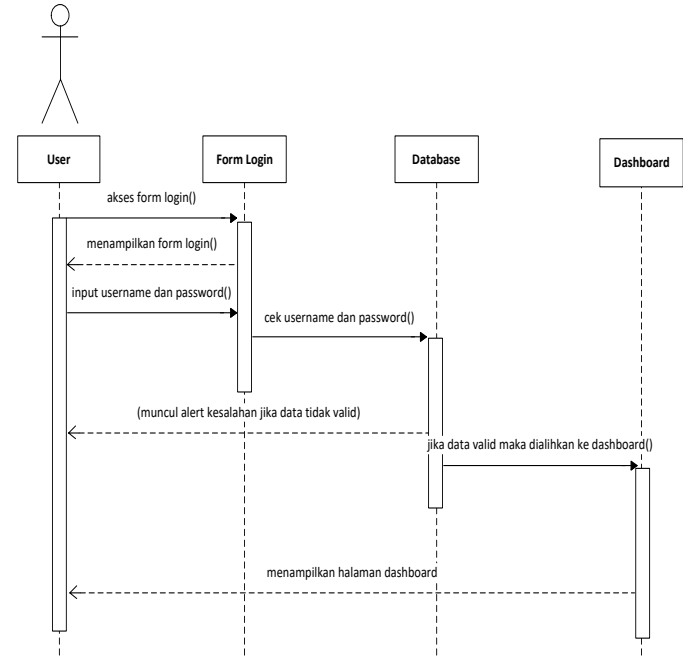

Gambar 8. Sequence Diagram Login User

c) Activity

Diagram Login

Administrator dan Register User

Activity diagram digunakan untuk menggambarkan aliran kerja dari sebuah sistem yang dapat dilihat pada gambar 9., yang menjelaskan proses aktivitas adminstrator melakukan login agar dapat mengakses ke dalam dashboard admin, aplikasi pengelolaan dan peminjaman sarana prasarana menggunakan metode push notification. Sedangkan activity diagram register user dapat dilihat pada gambar 10 yang menjelaskan proses user mengakses aplikasi kemudian menampilkan form register sebagai langkah untuk meminjam sarana dan prasarana.

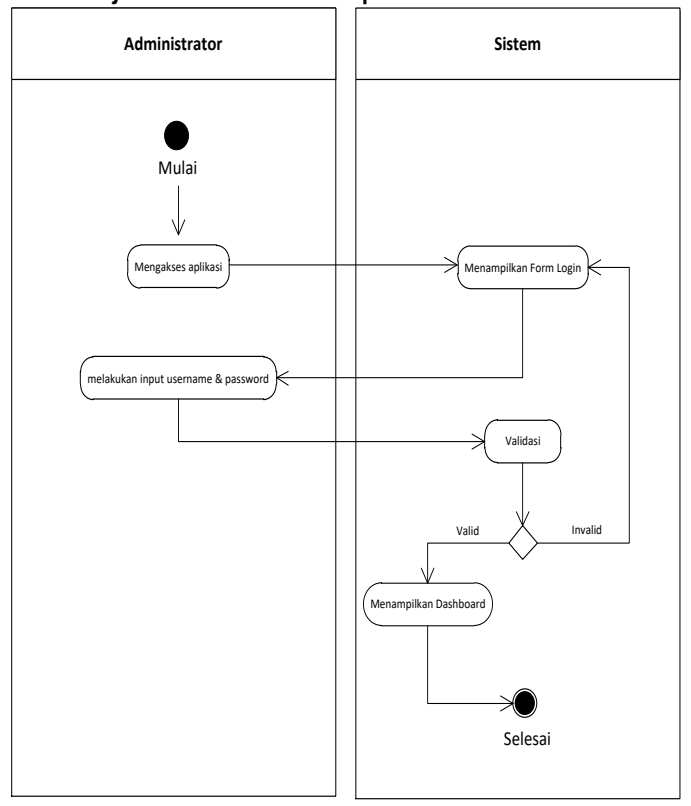

Gambar 9. Activity Diagram Login Admin 


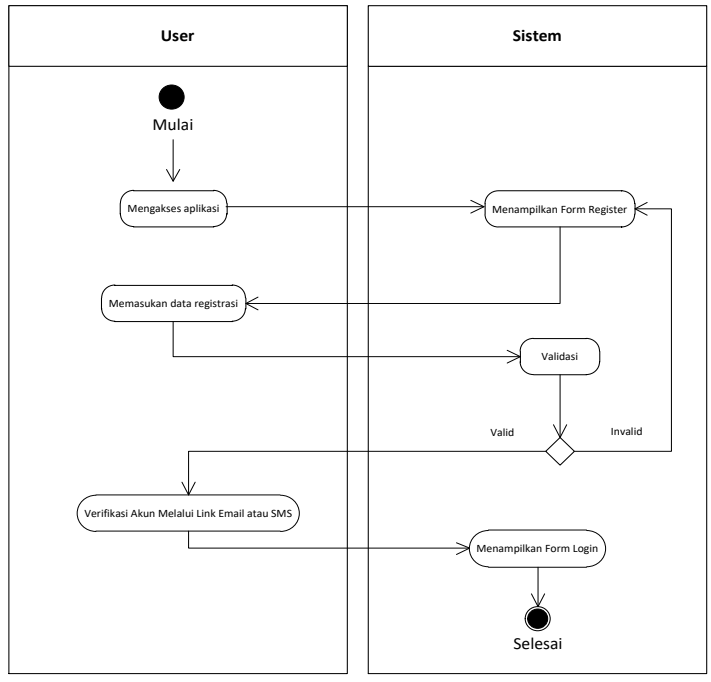

Gambar 10. Activity Diagram Register User

\section{d) Class Diagram}

Class diagram digunakan untuk menampilkan kelas-kelas dan paket didalam sistem untuk memberikan gambaran berkaitan dengan sistem statis dan relasi antar muka, penjelasan berkaitan class diagram dapat dilihat pada gambar 11., yang menjelaskan antar tabel pada aplikasi pengelolaan dan pemijaman sarana prasarana.

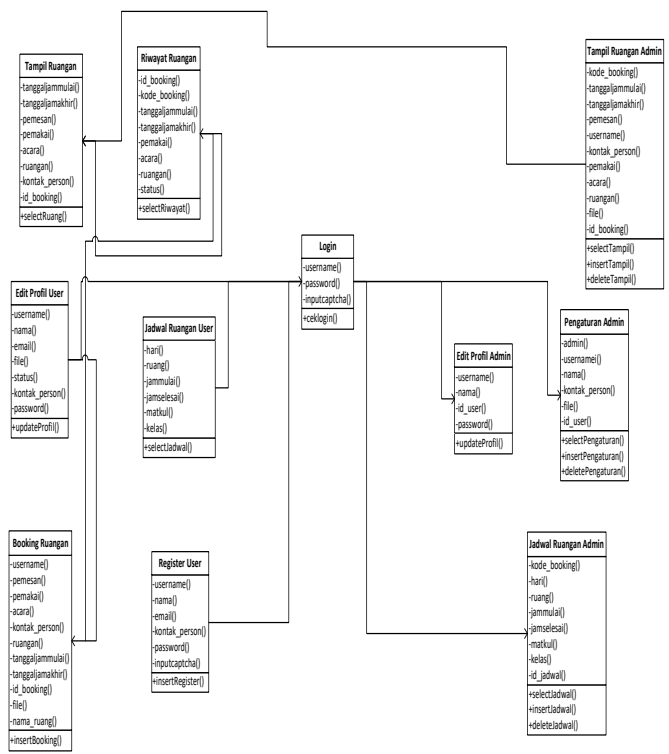

Gambar 11. Class Diagram antar tabel

\section{Hasil Interface}

a) Menu Login Utama

Menu login utama merupakan tampilan utama yang dijalankan saat aplikasi baru pertama kali terbuka, menu ini hanya dapat diakses oleh staf laboran dan kerumah tanggaan bidang sarana prasarana. Pada menu ini menggunakan akses kedalam sistem dengan mengisikan username dan password yang telah tersimpan didalam database.

\section{Login Admin \\ Usorncume \\ Password}

\section{LOGIN}

Gambar 12. Layout Login Admin

b) Layout Halaman Beranda Administrator Layout ini menjelaskan tentang layout halaman beranda administrator yang menjelaskan berbagai fitur yang dapat digunakan oleg admin.

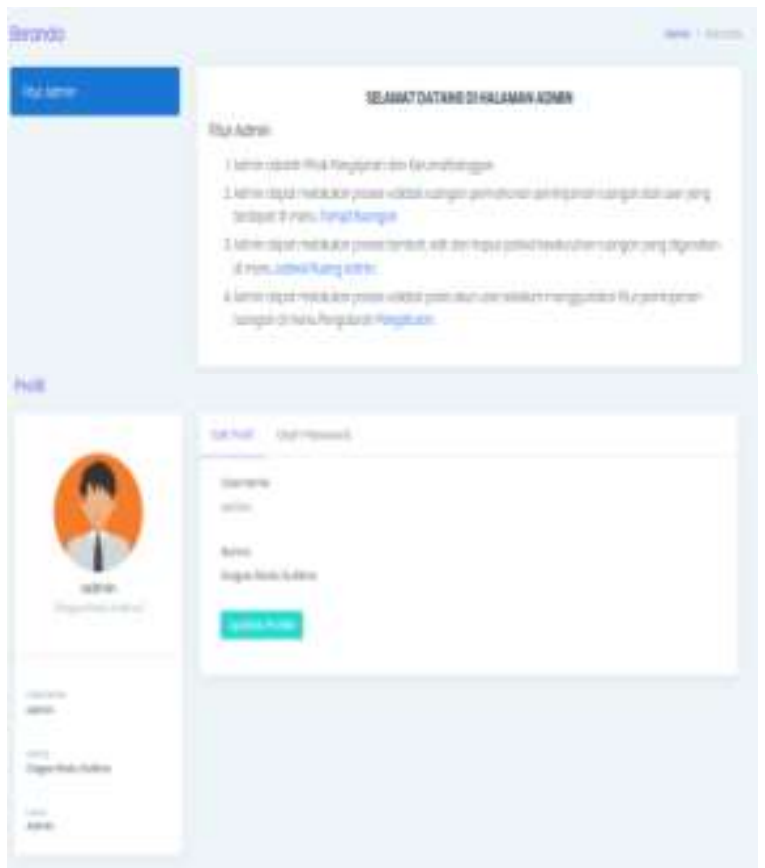

Gambar 13. Layout halaman beranda administrator

c) Layout Fitur User

Pada menu fitur user digunakan sebagai portal masuk kedalam sistem untuk mahasiswa, menu login mahasiswa dapat akses oleh user yang memiliki hak akses sebagai mahasiswa, berikut tampilan menu login mahasiswa dapat dilihat pada gambar 14. 


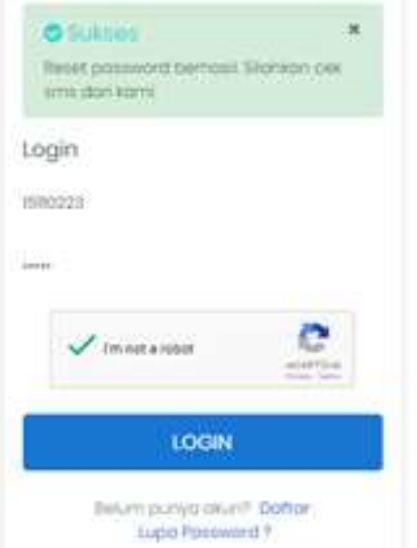

Gambar 14. Layout halaman login user

d) Layout Register User

Layout ini menjelaskan tentang layout register user, pengguna dapat memasukan data untuk proses peminjaman maka lakukan terlebih dahulu register agar dapat melakukan fitur didalam aplikasi ini.

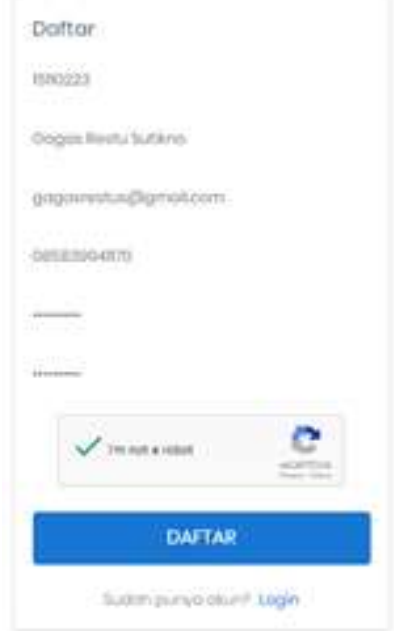

Gambar 15. Layout Register User e) Layout Push Notification Kode Register dan Peminjaman Telah Berakhir

Layout ini menjelaskan tentang bagaimana melakukan aktivasi kode register, pada halaman ini pengguna diminta untuk memasukan kode register yang telah terkirim melalui kontak yang didaftarkan, agar dapat masuk ke akun maka terlebih dahulu memasukan kode yang telah diterima dan apabila peminjaman telah berakhir maka akan menampilkan notifikasi berupa sms ketika user telah selesai melakukan peminjaman.

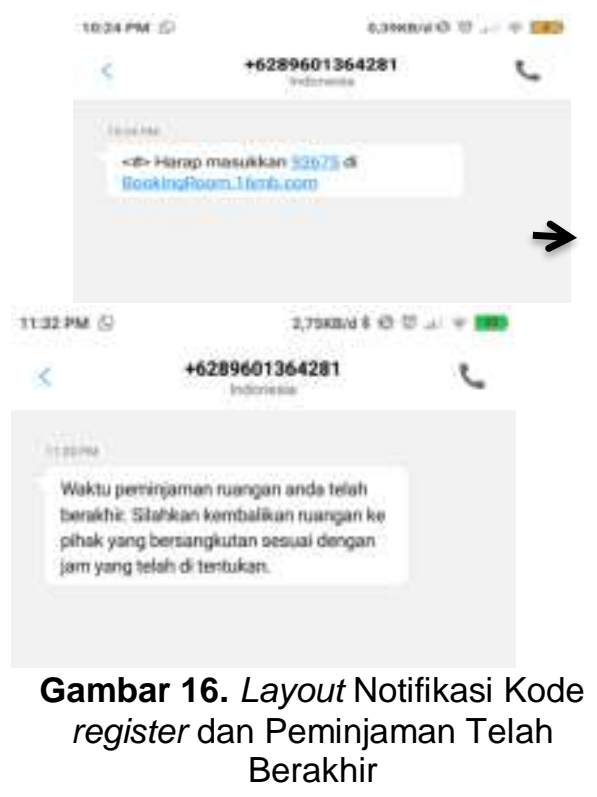

4. Pengujian (Testing)

Pada tahap pengujian yang dilakukan menggunakan pengujian unit testing penulisan kode-kode program dalam satuan unit terkecil secara individual, pada tahap testing setiap kali selesai penulisan kode program dan langsung testing pada fitur aplikasi yang telah dibuat untuk mengetahui apakah fitur tersebut berjalan sesuai dengan yang diinginkan atau tidak. Dan pada tahapan pengujian berikutnya dengan melakukan acceptance testing yaitu untuk menentukan apakah sistem yang dibangun telah memenuhi kriteria penerimaan serta menentukan apakah sistem tersebut dapat diterima atau tidak.

a) Unit Testing

Unit Testing pada aplikasi pengelolaan dan peminjaman sarana dan prasarana menggunakan push notification pengujian admin dan user. Pengujian tersebut merupakan pengujian program berdasarkan fungsi dari sistem untuk mengetahui kesalahan fungsi pada program dan dari hasil pengujian fitur dengan blackbox yang ada pada aplikasi pengelolaan dan peminjaman sarana prasarana ada dalam tabel dibawah ini:

Dari hasil pengujian dengan blackbox yang telah dilakukan dari semua fitur atau tombol dari setiap pengujian tidak semuanya di tampilkan dalam tabel, dari semua fitur yang di uji telah menunjukan hasil yang sesuai dengan harapan, sehingga dapat disimpulkan sistem yang di uji berhasil menampilkan semua pemberitahuan prosesnya. 
b) Acceptance Testing

Acceptance testing dilakukan dengan menggunakan metode kuisioner, perhitungan hasil kuisioner dilakukan menggunakan perhitungan skala likert menurut Sugiyoono (2017), skala likert digunakan untuk mengukur sikap, pendapat, dan persepsi seseorang atau kelompok orang tentang fenomena sosial. Sehingga dengan skala likert maka variabel yang akan diukur dijabarkan menjadi indikator variabel, kemudian indikator tersebut dijadikan sebagai titik tolak untuk menyusun item-item instrumen yang dapat berupa pernyataan atau pertanyaan. Acceptance testing sendiri dilakukan kepada mahasiswa internal Universitas Amikom Purwokerto.

Pada pengujian ini dilihat kualitas dari aplikasi pengelolaan dan peminjaman sarana prasarana dengan menggunakan teknologi push notification apakah fitur yang ada sudah sesuai dengan fitur yang dibutuhkan oleh pengguna (user). Pengujian ini juga dilakukan untuk mendapatkan tanggapan dari pengguna aplikasi tentang kelengkapan informasi dan fitur pada aplikasi pengelolaan dan peminjaman sarana prasarana. Pengujian admin dan user testing merupakan pengujian program berdasarkan fungsi dari program. Tujuan dari pengujian admin dan user testing ini adalah untuk menemukan kesalahan fungsi pada program. Dibawah ini dijelaskan rencana dan hasil pengujian fitur yang ada pada aplikasi Pengelolaan dan Peminjaman menggunakan Metode Push Notification:

Tabel 3. Rating Scale

\begin{tabular}{|c|c|}
\hline Nilai & Kriteria \\
\hline $81 \%-100 \%$ & Sangat Baik \\
\hline $61 \%-80 \%$ & Baik \\
\hline $41 \%-60 \%$ & Cukup \\
\hline $21 \%-40 \%$ & Tidak Baik \\
\hline $0 \%-20 \%$ & Sangat Tidak Baik \\
\hline
\end{tabular}

$$
\begin{aligned}
& \mathrm{SS}=5 \times 5 \times 30=750(100 \%) \\
& S=4 \times 5 \times 30=650(80 \%) \\
& \text { RG } \quad=3 \times 5 \times 30=450(60 \%) \\
& \text { TS }=2 \times 5 \times 30=300(40 \%) \\
& \text { STS } \quad=1 \times 5 \times 30=150(20 \%)
\end{aligned}
$$

Jumlah responden sebanyak 30 mahasiswa dengan jumlah pertanyaan 5 , jumlah nilai tertinggi 5 dan nilai terendah 1 . Rumus untuk menghitung kuisioner menggunakan skala likert (Rumus Index \% $=$ Total Skor / Skor Tertinggi $x$ 100)
(Sugiyono, 2017). Dari hasil kuisioner tersebut didapat hasil sebagai berikut :

Total Skor $=$ (Total Pemilih $\times$ Skor $)$

$$
\begin{aligned}
& =(18 \times 5)+(105 \times 4)+(27 \times 3)+(1 \times \\
& 2)+(0 \times 1) \\
& =90+420+81+2+0 \\
& =593
\end{aligned}
$$

Skor Tertinggi $=($ Nilai Tertinggi $\times$ Jumlah Pertanyaan $x$ Jumlah Responden)

$$
=(5 \times 5 \times 30)=750
$$

Rumus Index\% = Total Skor / Skor Tertinggi x $100=593 / 750 \times 100=79 \%$

Dari hasil perhitungan kuisioner yang dilakukan didapatkan prosentase sebanyak nilai $79 \%$ tergolong dalam kriteria baik. Sehingga dapat disimpulkan Aplikasi Pengelolaan dan Peminjaman sudah dapat digunakan untuk mempermudah proses peminjaman dan meminimalisir keterlambatan dalam pengembalian sarana prasarana di Universitas Amikom Purwokerto.

\section{Kesimpulan}

Peneliti telah berhasil membangun dan mengimplementasikan aplikasi pengelolaan dan peminjaman sarana dan prasarana menggunakan metode push notification pada Universitas Amikom Purwokerto dengan menggunakan fitur notifikasi SMS untuk memberitahukan kepada user bahwa proses peminjaman telah berakhir sehingga dapat meminimalisir keterlambatan pengembalian. Dari hasil sistem tersebut pengelolaan sarana dan prasarana dengan metode push notification dapat membantu menyelesaikan permasalahan yang ada, dari pengujian blackbox sendiri menunjukan bahwa aplikasi sesuai dengan yang diharapkan, sedangkan pengujian dengan menggunakan acceptance testing mendapatkan nilai $79 \%$ sehingga aplikasi dapat mempermudah proses peminjaman sarana dan prasarana. Untuk saran penelitian berikutnya bahwa sistem yang telah dibuat ini sebaiknya perlu diperhatikan agar kekurangan, kelemahan dapat segera dilakukan perbaikan kembali serta dapat dikembangkan dengan berbasis android agar lebih baik lagi dengan sistem yang sedang berjalan. 


\section{Referensi}

Akademik. (2012). Pedoman Akademik Universitas Amikom Purwokerto (2012th-2013th ed.).

Ayu, F., \& Permatasari, N. (2018). Perancangan Sistem Informasi Pengolahan Data Praktek Kerja Lapangan (Pkl) Pada Devisi Humas Pt. Pegadaian. Intra-Tech, 2(2), 1226.

Faisol, A., \& Rahmadianto, F. (2019). Realtime Notification Pada Aplikasi Berbasis Web Menggunakan Firebase Cloud Messaging ( $\mathrm{Fcm})$. Jurnal Mnemonic, 1(2), 14-17. https://doi.org/10.36040/mnemonic.v1i 2.32

Fridayanthie, E. wida. (2016). Rancang Bangun Sistem Informasi Permintaan Atk Berbasis Intranet (Studi Kasus: Kejaksaan Negeri Rangkasbitung). IOSR Journal of Economics and Finance, 3(1), 56. https://doi.org/https://doi.org/10.3929/ ethz-b-000238666

Isikligil, E., Samakay, S., \& Kılınç, D. (2017). A Prototype Framework for High Performance Push Notifications. International Journal of Computer Applications, 166(10), 8-11.

Pahlevi, O., Mulyani, A., \& Khoir, M. (2018). Sistem Informasi Inventori Barang Menggunakan Metode Object Oriented Di Pt. Livaza Teknologi Indonesia Jakarta. Jurnal PROSISKO, 5(1). https://livaza.com/.
Putra, I. P., Junaidi, A., Handayani, P., \& Yunita, Y. (2019). Sistem Informasi Perpustakaan Pada Madrasah Aliyah Negeri 16 Jakarta Kota Jakarta Barat. Jurnal Informatika, 6(2), 293299.

Putri, M. E., \& Wulandari, D. A. N. (2016). Sistem Informasi Monitoring Siswa Berbasis Web Dan SMS Gateway Pada SMK Negeri 37 Jakarta. Jurnal Teknik Komputer AMIK BSI, II(2), 4955.

Rahmatulloh, A., Rachman, A. N., Anwar, F., Informatika, J., Teknik, F., \& Siliwangi, U. (2019). Implementasi Web Push Notification Pada Sistem Informasi Applied Web Push Notification Uses Push Js in the Archive. Jurnal Teknologi Informasi Dan IImu Komputer (JTIIK), 6(3). https://doi.org/10.25126/jtiik.20196936

Wangsaputra, M., Prasetya, K., Hery, \& E. Widjaja, A. (2016). Pengembangan Aplikasi Dengan Fitur Push Notification Untuk Mendukung Pendistribusian Informasi Di Fakultas. Seminar Nasional Sistem Informasi Indonesia, 55-60.

Wijaya, H. O. L. (2017). Penerapan Metode Waterfall Pada Sistem Informasi Pendaftaran Pasien Rawat Jalan Berbasis Web Mobile. Jurnal Sisfokom (Sistem Informasi Dan Komputer), 6(2), 80. https://doi.org/10.32736/sisfokom.v6i2 .251 